\title{
Effects of Stochastic Flood Disturbance on Adult Wood Turtles, Glyptemys insculpta, in Massachusetts
}

\author{
Michael T. Jones ${ }^{1,2,3}$ and Paul R. SieverT ${ }^{2,3}$ \\ ${ }^{1}$ Organismic and Evolutionary Biology, Department of Biology, Morrill Science Center, University of Massachusetts Amherst, \\ Amherst, Massachusetts 01003 USA; corresponding author e-mail: mtjones@bio.umass.edu \\ ${ }^{2}$ Wildlife and Fisheries Conservation, Department of Natural Resources Conservation, 160 Holdsworth Way, University of \\ Massachusetts Amherst, Amherst, Massachusetts 01003 USA \\ ${ }^{3}$ U.S. Geological Survey, Massachusetts Cooperative Fish and Wildlife Research Unit, Department of Natural Resources \\ Conservation, University of Massachusetts Amherst, Amherst, Massachusetts 01003 USA
}

Jones, Michael T., and Paul R. Sievert. 2009. Effects of stochastic flood disturbance on adult Wood Turtles, Glyptemys insculpta, in Massachusetts. Canadian Field-Naturalist 123(4): 313-322.

The homing ability of non-marine turtles has been studied in a variety of taxa, and many species appear to be capable of shortrange homing on the scale of several hundred meters or a few kilometers following experimental displacement. However, the behavioral response of turtles following a naturally caused displacement has seldom been reported. In this paper, we describe the effect of displacement ranging from 1.4 to $16.8 \mathrm{~km}$ (average $=4.8 \mathrm{~km}$ ) by severe floods in a stream system in Massachusetts. We radio-tracked 38 adult Wood Turtles (Glyptemys insculpta) at five separate sites in Franklin County, Massachusetts, for periods ranging from one to four activity seasons and documented the displacement of a total of 12 Wood Turtles during seven floods between 2004 and 2008. Based on the average rate of displacement per flood and annual flood frequency, we estimate that, during our study, floods displaced over $40 \%$ of this Wood Turtle subpopulation annually. We present evidence that displacement results in elevated mortality rates and that displaced Wood Turtles mate and nest in the year following displacement at rates well below average; on a longer time scale, however, displacement by flooding may be an important mechanism of population connectivity in some areas. We also present evidence that most Wood Turtles avoid stream segments with stream gradient steeper than $1 \%$; this may in part reflect an adaptation to avoid severe floods. Regional models and empirical data from stream gages suggest that flood intensity may currently be on an increasing trend. Conversion of upland from forest and fields to impervious surfaces and hardening of upstream riverbanks may have exacerbated recent flooding and decreased the resiliency of the riparian system to increased precipitation.

Key Words: Wood Turtle, Glyptemys insculpta, freshwater turtles, floods, rivers, disturbance, stream gradient, climate change, Massachusetts, New England.

Many species of non-marine turtle appear to be capable of "homing", or navigating toward familiar territory, after experimental displacement on the scale of several hundred meters or several kilometers. For example, homing has been experimentally demonstrated in the emydid species Clemmys guttata (Ernst 1968), Glyptemys insculpta (Carroll and Ehrenfeld 1978; Barzilay 1980), and Terrapene carolina (Nichols 1939; Gould 1957; Mathis and Moore 1988). Relatively large movements have been documented in free-ranging turtles, for example, Terrapene coahuila (to $9.7 \mathrm{~km}$; Howeth et al. 2008), Glyptemys insculpta (to $3.7 \mathrm{~km}$; Walde et al. 2007) and Gopherus agassizii (to over $32 \mathrm{~km}$; Schwalbe et al. 2002*).

Although the homing phenomenon has been explored through experimental displacement for nearly a century, natural causes of displacement are rarely reported or discussed. The sensing abilities that allow turtles to head in a homeward direction following displacement probably also assist turtles in locating and navigating to important landscape features within their home range, but regular displacement in an ancestral aquatic environment could have contributed to the adaptation of homing abilities. In many stream systems, floods are the most likely source of long-distance, involun- tary, non-lethal displacement of adult turtles, and these systems provide an opportunity to study both the effect of major stochastic flood disturbance on populations of stream-dwelling turtles and the behavioral response of individuals to displacement over multiple kilometers.

Flooding influences riparian ecosystems by altering channel geomorphology and floodplain vegetation, by connecting the primary stream corridor to isolated floodplain wetlands, by facilitating dispersal of organisms, and by drowning, injuring, or displacing individual animals (Goldthwait 1928; Collins et al. 1981; Hupp 1982; Jones 1996; Anderson et al. 2000). The size and frequency of floods are generally the products of complex interactions among land uses within a watershed, watershed area, tributary and main channel slope, valley shape, and precipitation frequency (Goldthwait 1928; Horton 1945; Wong 1963), although Wong (1963) demonstrated that mean annual floods in New England can be modeled using only stream length and average land slope, suggesting that large, highgradient streams are prone to floods of the largest volume and power. Floods are also more pronounced in streams with constrained valley walls (Wong 1963). In northern and high-elevation regions, winter and spring floods are generally more severe than summer floods, 
TABLE 1. Elevation, watershed area, and stream size at field sites in Franklin Country, Massachusetts, USA. For definitions of forested vs. agri-forested landscapes, see Saumure et al. (2007).

\begin{tabular}{cccccc}
\hline \hline Site & Elevation $(\mathrm{m})$ & $\begin{array}{c}\text { Watershed } \\
\text { area (ha) }\end{array}$ & $\begin{array}{c}\text { Average stream } \\
\text { width (m) }\end{array}$ & $\begin{array}{c}\text { Number of turtles } \\
\text { with transmitters }\end{array}$ & $\begin{array}{c}\text { Upland site } \\
\text { characteristics }\end{array}$ \\
\hline A & $221-268$ & 281 & 5.1 & 8 & Forest \\
B & $247-258$ & 418 & 7.5 & 9 & Agri-forest \\
C & $145-203$ & 1770 & 12.7 & 9 & Agri-forest \\
D & $91-96$ & 1987 & 15.48 & 11 & Forest \\
E & $41-49$ & 46227 & 50.7 & 11 & Agri-forest \\
\hline \hline
\end{tabular}

because, in addition to the compounding factor of snowmelt, streamside snowpack increases the height of the stream bank and constrains elevated flows (Erman et al. 1988).

The effect of floods on aquatic vertebrates, primarily fish, has been documented in several systems (e.g., Elwood and Waters 1969; Collins et al. 1981; Erman et al. 1988; Jowett and Richardson 1989; Strange et al. 1992). Several studies have indicated that seasonal flooding influences the behavior of individual turtles, for example, Jones (1996) found that Yellow-blotched Map Turtles (Graptemys flavimaculata) alter their behavior seasonally to accommodate or exploit high-flow conditions. Selman and Qualls (2008) subsequently presented evidence that Graptemys flavimaculata may have been negatively affected by flooding associated with Hurricane Katrina in 2005. Pluto and Bellis (1988) observed that Common (Northern) Map Turtles (Graptemys geographica) in Pennsylvania selected deep, slow riverine environments in the fall and made large upstream movements during low-flow conditions. Similarly, Moll and Legler (1971) reported downstream movements of Common Sliders (Trachemys scripta) during high-flow events, and Ernst (1974) documented habitat shifts, decreased recruitment, and increased depredation of adult Eastern Painted Turtles (Chrysemys picta) following Hurricane Agnes in 1972. Floods may negatively affect, or displace, terrestrial turtles: Stickel $(1948,1978)$ reported that although severe floods in 1945 did not have a negative impact on a Maryland population of the terrestrial Eastern Box Turtle (Terrapene carolina), floods in 1972 may have contributed to a marked population decline.

Additional studies have presented evidence for morphological distinction between populations of freshwater turtles in lentic and lotic habitats, suggesting that some riverine species develop body dimensions that reduce drag (e.g., Emys marmorata, Lubcke and Wilson 2007; Pseudemys concinna, Rivera 2008).

These studies do not specifically address populationand individual-level effects of displacement by large floods. Direct evidence of displacement by flooding is rare and is mostly confined to stream-dwelling species, e.g., Emys marmorata (see Ashton et al. 1997*; Rathbun et al. 2002; Alvarez 2005*), Glyptemys insculpta (Barzilay 1980, Sweeten 2008), and Kinosternon sonoriense (see Collins et al. 1981; Stitt and Swan 2000*).
Rathbun et al. (2002) suggest that winter flooding associated with the Mediterranean climate of California may have been partially responsible for terrestrial hibernation in some stream-dwelling populations of E. marmorata. These examples provide evidence of downstream displacement, but only Sweeten (2008) provides observations of extensive post-displacement behavior. Latham (1971) reported dead Glyptemys insculpta washed up in eastern Long Island after heavy rains in New England, providing anecdotal evidence that displacement caused by flooding may occasionally be extreme, and fatal.

Hypothetically, displacement by flooding, if not fatal, may significantly influence population dynamics. Displaced turtles may mate with downstream turtles, or they may lay eggs at the downstream location. If turtles move back to their original location, they may encounter habitats en route that are later incorporated into regular seasonal movements. Because some sites may be disproportionately affected by floods as a result of geomorphology, they may suffer a net loss of turtles over time if turtles do not successfully return. Overall, the direct effects of flooding on the behavior and survival of freshwater turtles have been largely neglected.

Wood Turtles are a good species in which to examine the effect of displacement by flooding on the behavior of individual turtles, as Wood Turtles occur in relatively flood-prone streams over large portions of their range. Although Wood Turtles are distributed across large portions of the northeastern United States and southeastern Canada (Ernst and Lovich 2009), high susceptibility to flooding could be an important reason why they are rare in or absent from high-relief, mountainous regions (although the lack of suitable riparian habitat and climatic variables are also likely significant limiting agents for Wood Turtles in northerly regions, e.g., Compton 1999). Because Wood Turtles overwinter underwater (Ernst and Lovich 2009), they may be limited to less flood-prone streams and stream segments than some other stream-dwelling turtles, such as E. marmorata and $K$. sonoriense, which are able to hibernate or aestivate on land (Rathbun et al. 2002; Ligon and Stones 2003; Ernst and Lovich 2009).

In this paper, we examine the effect of severe floods on adult Wood Turtles living in a stream system in Massachusetts. Based on simple models of floods in 
New England and preliminary observations of the species, we hypothesize that regular displacement of individual Wood Turtles will occur primarily in mountainous, relatively high-gradient streams, and we predict that surviving Wood Turtles displaced by flooding will influence the reproductive ecology of the downstream site by mating with local Wood Turtles and/or nesting at the downstream site. Because of their demonstrated homing ability, we predict that the majority of Wood Turtles will attempt to return to their upstream location if they survive the initial displacement. Finally, we predict that Wood Turtles in mountainous areas will select relatively low-gradient streams, an adaptation to minimize being displaced by flooding during hibernation.

\section{Study Area}

Surveys for adult Wood Turtles were conducted at 22 separate sites in western Massachusetts and central New Hampshire. Five sites in the same watershed in Franklin County, Massachusetts ("Franklin County Sites," denoted Sites A though E; exact localities are withheld for conservation purposes; Table 1; Figure 1 ), were studied intensively because the majority of displacement caused by flooding occurred there. We have limited most of our assessment to those sites, although the remaining 17 sites are used for comparative purposes.

The Franklin County sites consist of four sites (B through E) along $23 \mathrm{~km}$ of stream in one tributary basin and the main stem and a single site (Site A) on a neighboring tributary (Figure 1). The Franklin County sites range in elevation from 41 to $268 \mathrm{~m}$. The watershed of streams and rivers ranged from 281 ha to 47000 ha, and the width ranged from approximately $5 \mathrm{~m}$ to $50 \mathrm{~m}$ (Table 1 ). The stream on which all sites are centered flows through a generally agriforested landscape (Saumure et al. 2007), with some sites being almost entirely forested and others consisting largely of mixed agricultural fields and forest (Table 1). In general, the five Franklin County sites are more heavily forested than the remaining 17 sites, and one (Site D) is largely situated in a narrow valley. While the Franklin County sites exhibit a relatively wide range of 100 -m scale stream gradient from 0 to $5 \%$, the average stream gradient at these sites was $1.58 \%$, much higher than the average stream gradient of the remaining 17 sites $(0.49 \%)$ (Jones 2009).

\section{Methods}

\section{Field Surveys and Radiotelemetry}

We conducted surveys for Wood Turtles at daily to weekly intervals from April to November 2004; March to November 2005-07; and March to July 2008. Wood Turtles were located by searching stream banks, logjams, undercut banks, and streamside vegetation, following a protocol similar to that described by Compton et al. (2002), Arvisais et al. (2002), Saumure (2004),

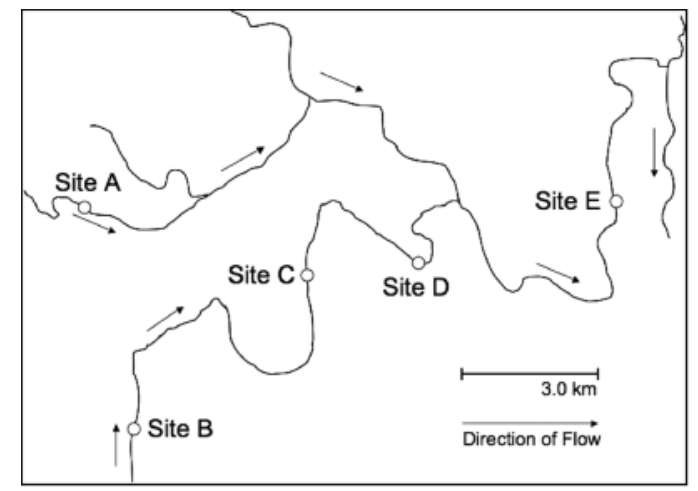

FIGURE 1. Primary Wood Turtle (Glyptemys insculpta) study area in Franklin County, Massachusetts, USA, showing approximate configuration of study sites.

and Saumure et al. (2007). Turtles were sexed (Ernst and Lovich 2009), approximately aged by counting growth rings on the left abdominal scute or, if the scute was partially to mostly worn, by estimating shell wear (Jones 2009). Wood Turtles older than one year were individually marked by notching the marginal scutes (Ernst et al. 1974), and all Wood Turtles were digitally photographed as a secondary means of identification. Seven measurements of carapace and plastron, including straight-carapace length (SCL), were taken to the nearest $0.25 \mathrm{~mm}$ using dial calipers (Jones 2009). Wood Turtles were classified as juveniles if they had visible new growth at the plastral midline (see Stickel 1978) and fewer than 9 lines of arrested growth (LAG).

Radio transmitters (MBFT-6, Lotek Wireless, Newmarket, Ontario; R2020, Advanced Telemetry Systems, Isanti, MN) were attached to a total of 170 Wood Turtles at 22 sites using orthodontic acrylic resin (BioCryl Resin, Great Lakes Orthodontics, Tonawanda, NY) (see Compton 1999). Of these, 38 radio transmitters were placed on turtles at the five Franklin County sites. Wood Turtles with body mass $<600 \mathrm{~g}$ were not equipped with transmitters to ensure that the weight of the transmitter (encased in acrylic) would not exceed $\sim 3 \%$ of turtle body mass. We placed transmitters on an approximately equal number of males and females at each site. Wood Turtles with transmitters were located by radiotelemetry between one and three times per week from the initial capture date until November of each year and beginning again in May the following year. For analysis purposes, we defined a complete turtle-year as consisting of $>25$ radio locations, collected at a minimum of weekly intervals, over the entire active season.

Locations of Wood Turtles were mapped in the field using handheld GPS (12-channel Etrex, Garmin Inc., Olathe, Kansas, USA) and entered into a Geographic Information System (GIS; ArcMap, ArcView 3.2a and Spatial Analyst, ESRI, Redlands, California, 
USA). Distances between locations were calculated using Microsoft Excel v. 11.5.1 (Microsoft Corporation, Redmond, Washington, USA) and ArcMap. Terrain and stream geomorphology data for each study site were derived using ArcMap.

Wood Turtles with transmitters were considered "displaced" if they appeared more than $1.4 \mathrm{~km}$ downstream of the limit of all previous observations immediately following a flood event. This threshold downstream distance was based on the 75th percentile "stream home range" (the total length of stream used in one year) of all radio-tracked Wood Turtles. Downstream movement is not direct evidence of displacement by flooding, and defining "displacement" is difficult because Wood Turtles regularly move large distances up- or downstream; for this reason, a heavy emphasis was placed on context. For example, following floods, many displaced Wood Turtles exhibited fresh injuries consistent with long transport over rocks, including broken marginal bone, broken limbs, damaged tails, and missing keratin.

\section{Stream Flow Analysis}

U.S. Geological Survey stream flow data (USGS $2008^{*}$ ) from one of the five Franklin County sites (Site C) were used to examine the magnitude of floods and to relate flood volume to observed displacement of Wood Turtles. Data from this gage were monitored remotely via the Internet from the University of Massachusetts Amherst, about 10 miles away, during most major rain events, so that Wood Turtles could be checked by radiotelemetry during or following the flood. Stream flow data from this site are collected at 15-min intervals and daily averages computed. Stream flow data are reported by the U.S. Geological Survey in cubic feet per second (cfs), but here we have reported flow measurements in SI units $\left(\mathrm{m}^{3}\right.$ per second, $\left.\mathrm{m}^{3} / \mathrm{s}\right)$.

We divided the average daily average stream flows associated with observed displacement by the annual daily average stream flow to derive a ratio for the purpose of identifying potential displacing events outside of the study area and study period. This ratio was used to evaluate historic conditions at this site, and to evaluate the possible prevalence of displacing floods at other sites in Massachusetts. By this measure, in our study system, a "displacing flood" occurs when daily flows exceed 14.5 times the average daily flow.

To assess how anomalous the study drainage might be and how extensively floods affect other Wood Turtle populations in the region, we analyzed stream flow records from 11 other streams in Massachusetts for their relative flood frequency and seasonality. To assess how frequently major floods disrupted each system, we multiplied the mean daily flow for each stream by 14.5, the multiplier associated with displacement at the Franklin County sites. We then counted how many events that met that criterion had occurred during the gaging history and the number of these events that occurred well within the active season for Wood Turtles
(May to September), when Wood Turtles are largely terrestrial, as opposed to the "aquatic" season (October to April).

\section{Analysis of Stream Gradient in Habitat Selected by Wood Turtles}

Because of the role played by stream gradient in the magnitude of seasonal floods (Wong 1963) and our hypothesis that the severity of flooding limits the local distribution of Wood Turtles in some mountainous areas, we examined the influence of stream gradient on the distribution of Wood Turtles at two scales in Massachusetts. Using digital terrain models (DTMs) in ArcMap, "home range" stream gradient values were derived for the continuous length of stream used by each of 110 radio-equipped Wood Turtles for which we had obtained an entire season of movement data. For comparison, we also estimated stream gradient of a paired, random, non-overlapping stream segment of a random length between 352 and $3520 \mathrm{~m}$ (the 25th and 95th percentile of all observed stream-based home range lengths from 2004 and 2005). The differences in means between the "used" and "random" stream segments were compared using a paired, two-tailed $t$-test.

\section{Results}

A total of 170 Wood Turtles were radio-tracked at 22 sites in Massachusetts and New Hampshire. Thirtyeight Wood Turtles were radio-tracked in Franklin County at Sites A-E, where the phenomenon of displacement by flooding was studied.

During our four-year study, seven disruptive floods occurred in the Franklin County watershed that resulted in the downstream displacement of adult Wood Turtles. The minimum average daily flow resulting in displacement was $24.35 \mathrm{~m}^{3} / \mathrm{s}$ (14.5 times average daily flow), including a record flood on 9 October 2005, when peak flow at Site C exceeded $248 \mathrm{~m}^{3} / \mathrm{s}$ (USGS 2008*). Displacing floods occurred in January, March, April, and October (Table 2). Peak 15-minute stream flow during these floods ranged from $64.17 \mathrm{~m}^{3} / \mathrm{s}$ to $248.40 \mathrm{~m}^{3} / \mathrm{s}$ (Table 2). During each flood that exceeded $24.35 \mathrm{~m}^{3} / \mathrm{s}$, between one and four Wood Turtles carrying transmitters were displaced from their overwintering site and transported downstream (Table 2).

During 42 years of record (June 1966 - July 2008), 21 displacing floods exceeding $24.35 \mathrm{~m}^{3} / \mathrm{s}$ occurred between October and April (when Wood Turtles are aquatic and most susceptible to displacement) (USGS $2008 *$ ). This equals an average annual winter displacing flood rate of 0.50 floods per year, considerably lower than the frequency observed during our study, 1.67 displacing floods per year. According to our method of determining "displacing floods" (multiplying average daily flows by 14.5), this site is in the 90th percentile of gaged streams in western Massachusetts (Table 3).

A minimum of 12 Wood Turtles at the Franklin County sites were displaced a total of 17 times, and 
TABLE 2. The number and date of floods at our field sites in Franklin County, Massachusetts, USA, that met or exceeded $24.85 \mathrm{~m}^{3} / \mathrm{s}$ mean daily flow between 8 April 2004 and 22 July 2008 at the U.S. Geological Survey stream gage near Site C.

\begin{tabular}{llccccc}
\hline \hline & $\begin{array}{c}\text { Tean } \\
\text { Time of peak } \\
\text { stream flow }\end{array}$ & $\begin{array}{c}\text { Maximum } \\
\text { daily flow } \\
\left(\mathrm{m}^{3} / \mathrm{s}\right)\end{array}$ & $\begin{array}{c}\text { Number of } \\
\text { displaced turtles } \\
\text { equipped with } \\
\text { transmitters }\end{array}$ & $\begin{array}{c}\text { Proportion of } \\
\text { turtles with } \\
\text { transmitters } \\
\text { displaced }\end{array}$ & $\begin{array}{c}\text { Number of } \\
\text { additional } \\
\text { displaced } \\
\text { turtles }\end{array}$ \\
\hline 3 April 2005 & 0400 & 35.82 & 81.89 & 3 & 0.19 & 0 \\
24 April 2005 & no data & 26.45 & no data & 1 & 0.05 & 0 \\
9 October 2005 & 1515 & 68.10 & 248.40 & 3 & 0.13 & 0 \\
15 October 2005 & 0115 & 29.48 & 64.17 & 2 & 0.09 & 0 \\
18 January 2006 & no data & 26.05 & no data & 1 & 0.11 & 0 \\
16 April 2007 & 1000 & 89.99 & 205.13 & 3 & 1.00 & 3 \\
8 March 2008 & 1845 & 24.35 & 72.52 & 1 & 0.17 & 0 \\
\hline \hline
\end{tabular}

3 of these turtles were displaced multiple times. Nine Wood Turtles were carrying transmitters when they were displaced or buried during floods, and 3 additional Wood Turtles, which had been radiotracked earlier in the study, were captured and again equipped with transmitters following floods. We identified these 3 animals by their marginal notches and confirmed their identity using the digital photographs taken upon their initial capture. Although at least 12 Wood Turtles (9 equipped with transmitters at the time of displacement plus 3 Wood Turtles previously radio-tracked) were displaced during flooding during this study, only 9 were located at least once following displacement. Known displacement distances for these ranged from 1.4 to $16.8 \mathrm{~km}$ and averaged $4.8 \mathrm{~km}$. We observed an average displacement rate per disruptive flood of $25 \%$ in our sample of Wood Turtles equipped with transmitters. By averaging the proportion of Wood Turtles displaced in each flood and multiplying it by the average number of displacing floods per year (1.67, see above), we extrapolate an average annual displacement rate at the Franklin County sites during the study period of $41.5 \%$ of the adult population. This may be an overestimate, in part because we have included a potentially anomalous event in which 3 Wood Turtles carrying transmitters were displaced on 16 April 2007 , representing all of the Wood Turtles equipped with transmitters in the basin at that time. Excluding the flood on 16 April 2007 on the grounds of small sample size $(n=3)$, we estimate an average annual displacement rate of $20.6 \%$.

Of the four adult female Wood Turtles recovered following displacement and radio-tracked during the following nesting cycle, only one became gravid. The displaced Wood Turtle that nested following displacement in 2005 (\#75) did not nest in 2006, following a much larger displacement. This annual nesting rate of about $25 \%$ observed in displaced Wood Turtles is substantially lower than the overall annual nesting rate observed in western Massachusetts (71\%: Jones 2009).

No displaced Wood Turtles were observed copulating while at a downstream (i.e., displacement) location.
When Wood Turtles ended up in deep-walled ravines, such as at Site D, animals without exception sought high ground $(n=3)$, moving to hayfields and clearcuts more than $200 \mathrm{~m}$ from the stream and up to $110 \mathrm{~m}$ above it.

Following displacement by a flood, Wood Turtles were recovered in segments of low-gradient stream, adjacent to deep pools in large rivers, behind Beaver (Castor canadensis) dams that were not destroyed by the flood, and behind defunct dams. Three of nine (33\%) displaced Wood Turtles were recovered above a single, defunct dam dating from the 1890s.

\section{Additional Wood Turtles Possibly Displaced}

It is worthy of note that a major flood (mean daily discharge $=30.02 \mathrm{~m}^{3} / \mathrm{s}$ ) occurred on 1 April 2004 , only days prior to the start of initial surveys for this project. We suspect that several Wood Turtles initially captured in the spring of 2004 had been displaced in a recent flood, either the 1 April 2004 flood noted above or an earlier event. These animals exhibited aggregate symptoms and behaviors similar to the 12 animals known to have been displaced. We have broadly classed these symptoms and behaviors as follows: (1) fresh injuries to shell, limbs, or tail, typically in the form of cracked or chipped marginal bone and missing keratin; (2) sudden large movement upstream, sometimes followed by year(s) of sedentary behavior at an upstream site; and (3) anomalous overland movement of extreme length that is difficult to record because the animal suddenly moves out of radiotelemetry range in an unpredictable direction. At least 11 additional Wood Turtles exhibited a sufficient combination of these physical or behavioral symptoms to lead us to suspect that some portion of them had been displaced prior to being equipped with transmitters. Still, this is a cautionary assessment, because for each symptom listed above, several other plausible explanations exist.

\section{Mortality During and After Floods}

Wood Turtles displaced by flooding typically survived the initial displacement; however, we found evidence that mortality rates resulting from infection, mammal attacks, and unknown causes are higher in 


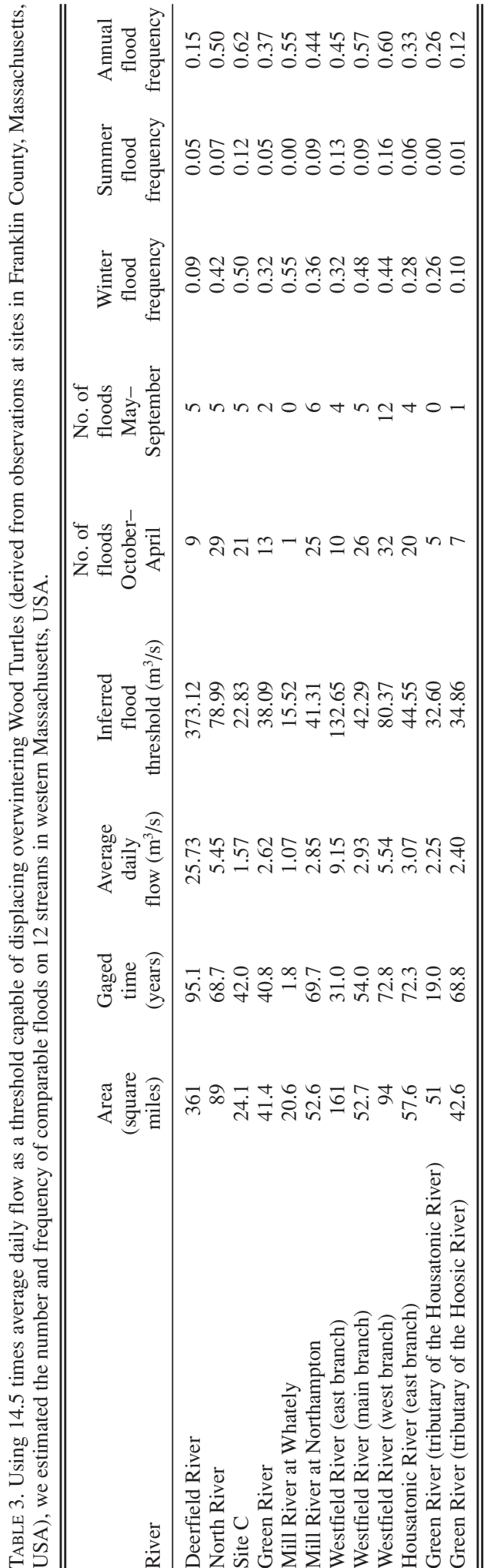

displaced Wood Turtles than in non-displaced Wood Turtles.

Of the nine Wood Turtles that were located and radiotracked during the year following their displacement, three $(33 \%)$ died within one year of displacement. Of these, two Wood Turtles (female \#66 and female \#396) were apparently killed by mammals 74 and 42 days following displacement, respectively. One male (\#222) died of unknown causes during the winter following displacement, and his decomposed remains were recovered on a riverbank the following spring. It is noteworthy that five Wood Turtles (two of which had been displaced to Site D the previous year) were transported from sites $\mathrm{C}$ and $\mathrm{D}$ over a dam $19 \mathrm{~m}$ high and concurrently lost their transmitters; the post-displacement mortality rate outlined above is conservative because three of the Wood Turtles displaced over the dam have no post-displacement radiolocations (F59, F2000, M1000) and cannot be included in the sample.

The mortality rate of the nine radio-tracked displaced Wood Turtles ( 3 of 9; 33\%) in the year following displacement is significantly higher than that observed in the first year of radiotelemetry of the 158 non-displaced Wood Turtles (11 of 158; 7\%) using a Fisher exact test $(P=0.0294)$ (Quinn and Keough 2002).

\section{Homing}

Of the nine Wood Turtles radio-tracked the year following displacement, three clearly initiated a return to their original location, and two of those successfully reached their original home range within one year. Two of the homing female Wood Turtles (\#75 and \#66) covered meandering distances of 3.5 and $1.2 \mathrm{~km}$ along the stream corridor (e.g., Figure 2), and one (\#61) returned largely overland. This Wood Turtle successfully homed a straight-line distance of $2.5 \mathrm{~km}$ (meandering distance of $3.7 \mathrm{~km}$ ) in 47 days (Figure 3). One displaced male, \#107, was displaced from Site B to Site $\mathrm{C}$, and subsequently displaced to Site $\mathrm{D}$, without initiating a return upstream. Another male (\#276), displaced from Site A to Site B, subsequently walked overland to Site C, the opposite direction from his observed origin.

\section{Stream Gradient Analysis}

Individual Wood Turtles throughout the Franklin County sites occupied stream home ranges with channel gradient significantly lower than available (paired two-tailed $t$ test, mean used $=0.58 \%$, mean random $=$ $1.27 \%, n=38, P=0.0007 ; t$ Stat $=-3.71)$. Wood Turtles at our remaining sites in Massachusetts were not associated with significantly lower stream gradient than that generally available (mean used $=0.36 \%$, mean random $=0.49 \%, n=72, P=0.2124 ; t$ Stat $=-1.258)$. Across sites, $91 \%$ of Wood Turtle home ranges were associated with stream gradient $<1 \%$.

\section{Discussion}

Our findings have several implications for the conservation of Wood Turtles in New England, and they 


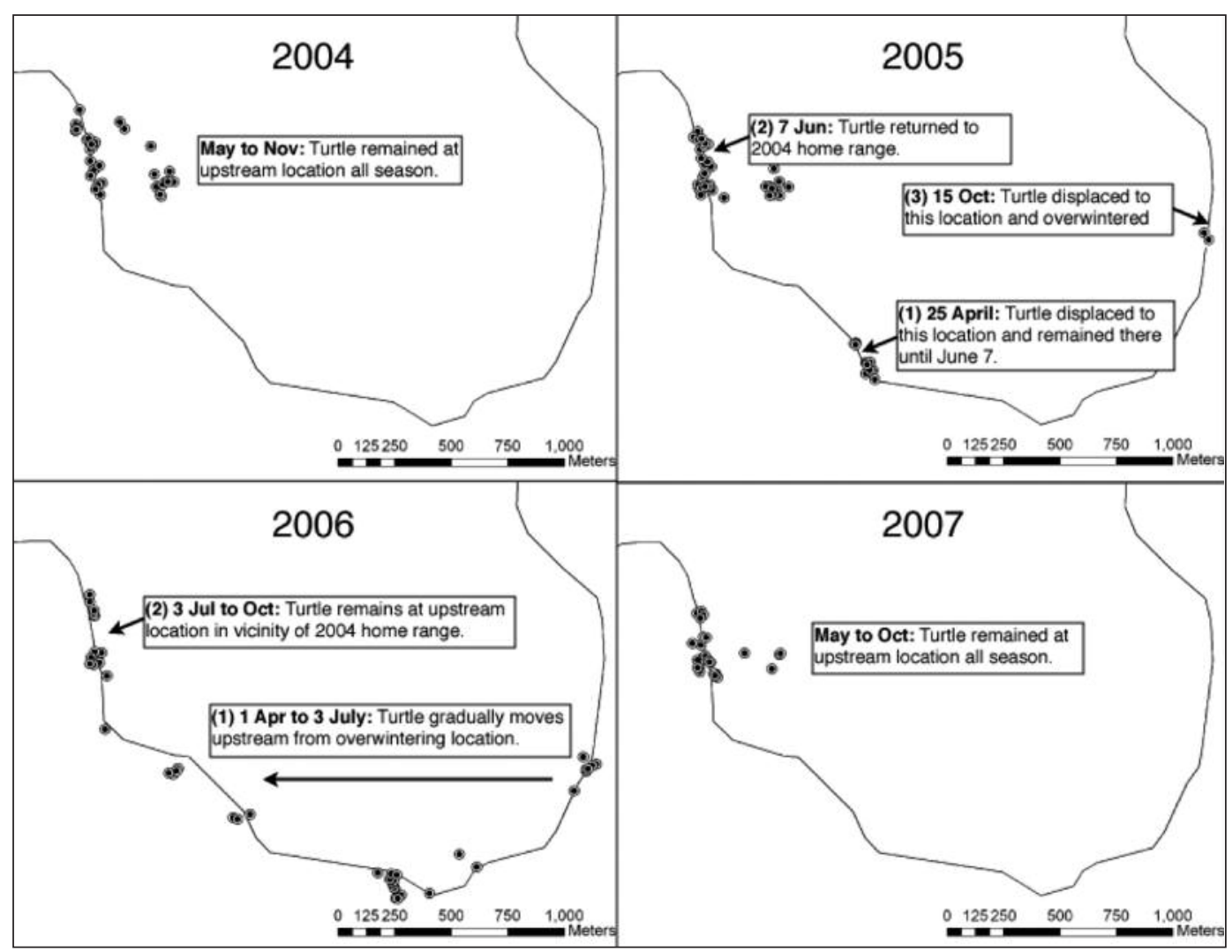

FIGURE 2. Annual home ranges of adult Wood Turtle (Glyptemys insculpta) female \#75 at the upstream portion of Site C, Franklin County, Massachusetts, USA, illustrating displacement events in 2005 and 2006 and return to original home range via the stream corridor.

may be applicable in some instances to the conservation of other riverine turtle species. Seasonal floods are an example of a stochastic environmental disturbance that clearly is capable of displacing adult Wood Turtles on a relatively frequent basis in our study area, and this flooding appears to exert a negative influence on the local population of Wood Turtles. While displacement by flooding may influence genetic structure within and between watersheds by linking populations that are not behaviorally connected and may represent an important dispersal and/or connectivity mechanism in unfragmented systems, displacement by flooding can also result in Wood Turtles being transported to unsuitable, atypical, unprotected or fragmented habitats. Although we note that caution should be used in artificially characterizing habitats as "fragmented" (see McIntyre and Hobbs 1999), we suggest that displacement from relatively unfragmented sites to more fragmented sites may mean that floods today have the potential to exert a stronger negative influence on Wood Turtle populations than prior to extensive urbanization.
Current projections indicate that the North American climate is becoming increasingly variable, meaning that there may be more pronounced wet and dry years (Watterson 2005; Morris et al. 2008), and also that precipitation will increase overall in the northeastern United States (Meehl et al. 2005). Together, these projections suggest that floods in the northeast will be become more frequent and more severe. Agricultural and residential development within the watershed has decreased the resiliency of the landscape to extreme precipitation events (DeNormandie et al. 2009*), but it is not clear whether the local landscape is becoming more or less resilient to heavy precipitation. Generally, the region is experiencing a reforestation trend and Beavers have returned after a 150 -year absence. Beavers may improve landscape resiliency to increased precipitation by creating large wetlands (Jackson and Decker 1995*). However, forest and fields continue to be converted to development (DeNormandie et al. 2009*), and stream bank hardening (riprap or concrete retaining walls) remains a common solution to flood 


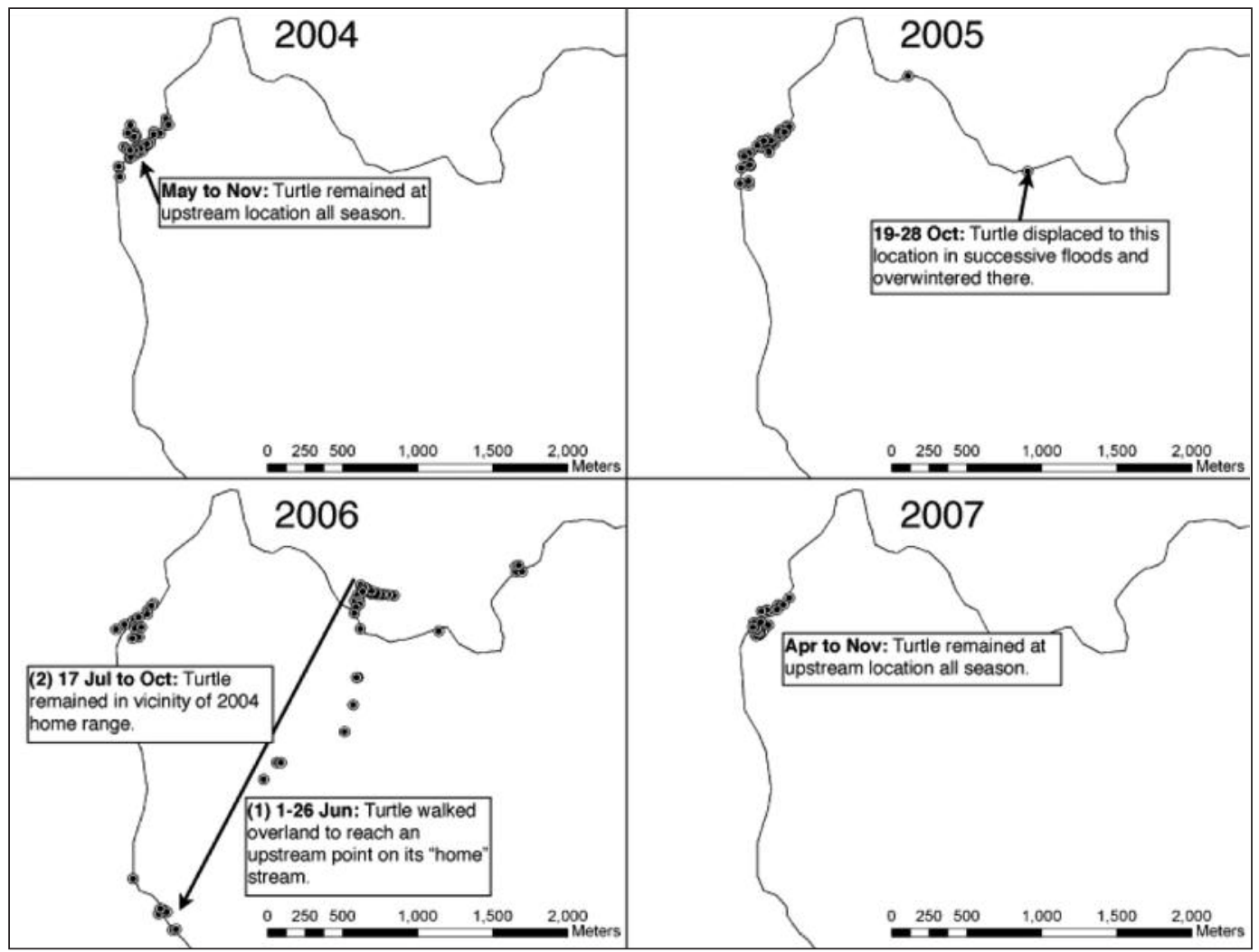

FIGURE 3. Annual home ranges of subadult Wood Turtle (Glyptemys insculpta) female \#61 at Site C, Franklin County, Massachusetts, USA, in 2004 and 2005, at Site D in 2006, and at Site C in 2007. This illustrates the Wood Turtle's displacement from Site C to Site D in the fall of 2005, a subsequent overland movement to the upstream portion of Site $\mathrm{C}$ in the summer of 2006, and subsequent downstream movement to original home range in summer 2006.

damage, potentially increasing the severity of future floods. Combined, increased precipitation is likely to result in larger floods that exert a greater impact on Wood Turtle populations through displacement of individuals.

Increasing flood severity in the New England region could exert greater pressure on Wood Turtle populations by increasing the frequency with which Wood Turtles are displaced. Even relatively remote populations that are apparently not affected by common sources of adult mortality such as road kill (Jones 2009) or agricultural activities (Saumure et al. 2007; Jones 2009) may be negatively affected by an existing or increasing flood regime. Displacement by flooding represents a hidden or cryptic source of mortality that is difficult to monitor, but which may influence population dynamics.

Several Wood Turtles in our study population exhibited the ability to return home following natural displacement, although most were unable to do so within the time we observed them, partly resulting from elevated mortality associated with displacement. At least one displaced Wood Turtle in our study returned to her initial capture site by traveling over land, indicating that Wood Turtles are not constrained to river corridors when returning home after floods, although they may preferentially use them as corridors (see Barzilay 1980). Wood Turtles displaced great distances downstream may be exposed to roads, new habitat features, and unfamiliar Wood Turtle populations while homing, especially if they cross over land. It is possible that high-quality habitat encountered while homing may be later incorporated into the home range. Overall, the average distance that Wood Turtles in our study were displaced $(4.8 \mathrm{~km})$ is not greatly different from the distances traveled by homing Wood Turtles reported by Carroll and Ehrenfeld (1978) and Barzilay (1980). Barzilay (1980) proposed that olfaction and familiarity with visual landmarks are more important to homing navigation than geomagnetic or solar cues; our research indicates that the physical stress associated with displacement, which appears to elevate mortality rates, also may decrease homing ability.

In our study, a large dam appeared to play a role in stopping the downstream transport of displaced Wood Turtles. In similar situations (relatively flood-prone 
streams with a Wood Turtle population), the effects of dam removal on up- and downstream Wood Turtle populations should be evaluated during re-licensing and long-term planning.

Within a small area, streams and rivers vary in the degree to which they are prone to flooding. Wood Turtle populations in less flood-prone streams may represent more predictable and stable conservation opportunities because individuals are probably displaced off-site at a lower rate. Because management and conservation opportunities for Wood Turtles are often constrained to a relatively small scale (i.e., smaller than the whole watershed), it is important for land managers to consider in their planning the potential effects of displacement caused by flooding.

\section{Acknowledgments}

This research was supported by grants from the Massachusetts Natural Heritage and Endangered Species Program, Sweet Water Trust, the Turtle Conservation Project, Mirage Studios, the University of Massachusetts Natural History Collections, and the A.V. Stout Fund. L. Willey, B. Compton, B. Crowley, Z. Dowling, B. Dunphy, S. Fowle, L. Johnson, C. Landrey, K. Lopardo, and D. Yorks provided excellent field support. This research was conducted under a permit from the Massachusetts Division of Fisheries and Wildlife (permit 138.08SCRA). Our field methods were approved by the University of Massachusetts Institutional Animal Care and Use Committee (protocols 24-02-01 and 27-02-02). L. L. Willey, B. Dunphy, and four anonymous reviewers provided very useful feedback.

Documents Cited (marked * in text)

Alvarez, F. 2005. Shellshocked turtles go home. Los Angeles Times: 9 August 2005.

Ashton, D. T., A. J. Lind, and D. E. Schlick. 1997. Western Pond Turtle (Clemmys marmorata) Natural History. U.S. Forest Service Pacific Southwest Research Station, Arcata, California. 22 pages.

DeNormandie, J., C. Corcoran, and J. J. Clarke. 2009. Losing Ground: Beyond the Footprint. Massachusetts Audubon Society, Lincoln, MA, USA. http://www.mass audubon.org/PDF/advocacy/losingground/LosingGround _web.pdf, including online interactive landscape statistics at http://www.massaudubon.org/losingground/stats.php.

Jackson, S., and T. Decker. 1995. Beavers in Massachusetts: natural history, benefits, and ways to resolve conflicts between people and beavers. University of Massachusetts Extension Service, Amherst, Massachusetts.

Schwalbe, C. R., T. Edwards, E. W. Stitt, R. Averill-Murray, and D. Swann. 2002. Desert Tortoises in a changing landscape: a long-term study at Saguaro National Park. Final report to Western National Parks Association and Saguaro National Park.

Stitt, E. W., and D. E. Swan. 2000. Sonoran Mud Turtles and surface water availability at Saguaro National Park, Pima County, Arizona. Final Report to the Western National Parks Association. Research Grant \#05-10. http://www. wnpa.org/research/sagu05-10.pdf.
United States Geologic Survey (USGS). 2008. Streamflow Data for Massachusetts. http://waterdata.usgs.gov/ma/nwis/ current/?type $=$ flow.

University of Massachusetts Landscape Ecology Lab (UMass LandEco). 2005. Spatial data for Massachusetts. http://www.umass.edu/landeco.

\section{Literature Cited}

Anderson, D. C., K. R. Wilson, M. S. Miller, and M. Falck. 2000. Movement patterns of riparian small mammals during predictable floodplain inundation. Journal of Mammalogy 81: 1087-1099.

Arvisais, M., J.-C. Bourgeois, E. Levesque, C. Daigle, D. Masse, and J. Jutras. 2002. Home range and movements of a Wood Turtle (Clemmys insculpta) population at the northern limit of its range. Canadian Journal of Zoology 80: 402-408.

Barzilay, S. S. 1980. Orientation and homing of the Wood Turtle (Clemmys insculpta). Unpublished Ph.D. dissertation, State University of New Jersey, New Brunswick, New Jersey.

Carroll, T. E., and D. W. Ehrenfeld. 1978. Intermediaterange homing in the Wood Turtle, Clemmys insculpta. Copeia 1978: 117-126.

Collins, J. P., C. Young, J. Howell, and W. L. Minckley. 1981. Impact of flooding in a Sonoran Desert stream, including elimination of an endangered fish population (Poeciliopsis o. occidentalis, Poeciliidae). Southwestern Naturalist 26: 415-423.

Compton, B. W. 1999. Ecology and conservation of the Wood Turtle (Clemmys insculpta) in Maine. Unpublished M.S. thesis, University of Maine, Orono, Maine.

Compton, B. W., J. M. Rhymer, and M. McCollough. 2002. Habitat selection by Wood Turtles (Clemmys insculpta): an application of paired logistic regression. Ecology 83: 833-843.

Elwood, J. W., and T. F. Waters. 1969. Effects of floods on food consumption and production rates of a stream Brook Trout population. Transactions of the American Fisheries Society 98: 253-262.

Erman, D. C., E. D. Andrews, and M. Yoder-Williams. 1988. Effects of winter floods on fishes in the Sierra Nevada. Canadian Journal of Fisheries and Aquatic Sciences 45: 2195-2200.

Ernst, C. H. 1968. Homing ability in the Spotted Turtle, Clemmys guttata (Schneider). Herpetologica 24: 77-78.

Ernst, C. H. 1974. Effects of Hurricane Agnes on a Painted Turtle population. Journal of Herpetology 8: 327-240.

Ernst, C. H., and J. E. Lovich. 2009. Turtles of the United States and Canada. 2nd edition. Johns Hopkins University Press, Baltimore, Maryland.

Ernst, C. H., M. F. Hershey, and R. W. Barbour. 1974. A new coding system for hard-shelled turtles. Kentucky Academy of Science 35: 27-28.

Goldthwait, J. W. 1928. The gathering of floods in the Connecticut River system. Geographical Review 18: 428-445.

Gould, E. 1957. Orientation in box turtles, Terrapene $c$. carolina (Linnaeus). Biological Bulletin 112: 336-348.

Horton, R. E. 1945. Erosional development of streams and their drainage basins: hydro-physical approach to quantitative morphology. Geological Society of America Bulletin 56: 275-370.

Howeth, J. G., S. E. McGaugh, and D. A. Hendrickson. 2008. Contrasting demographic and genetic estimates of dispersal in the endangered Coahuilan Box Turtle: a con- 
temporary approach to conservation. Molecular Ecology 17: 4209-4221.

Hupp, C. R. 1982. Stream grade variation and riparian-forest ecology along Passage Creek, Virginia. Bulletin of the Torrey Botanical Club 109: 488-499.

Jones, M. T. 2009. Spatial ecology, population structure, and conservation of the Wood Turtle, Glyptemys insculpta, in central New England. Unpublished Ph.D. dissertation, University of Massachusetts, Amherst, Massachusetts.

Jones, R. L. 1996. Home range and seasonal movements of the turtle Graptemys flavimaculata. Journal of Herpetology 30: 376-385.

Jowett, I. G., and J. Richardson. 1989. Effects of a severe flood on instream habitat and trout populations in seven New Zealand rivers. New Zealand Journal of Marine and Freshwater Research 23: 11-17.

Latham, R. 1971. Dead Wood Turtles found on eastern Long Island. Engelhardtia 4: 32.

Ligon, D. B., and P. A. Stones. 2003. Radiotelemetry reveals terrestrial estivation in Sonoran Mud Turtles (Kinosternon sonoriense). Journal of Herpetology 37: 750-754.

Lubcke, G. M., and D. S. Wilson. 2007. Variation in shell morphology of the Western Pond Turtle (Actinemys marmorata Baird and Girard) from three aquatic habitats in northern California. Journal of Herpetology 41: 107-114.

Mathis, A., and F. R. Moore. 1988. Geomagnetism and the homeward orientation of the box turtle, Terrapene carolina. Ethology 78: 265-274.

McIntyre, S., and R. Hobbs. 1999. A framework for conceptualizing human effects on landscapes and its relevance to management and research models. Conservation Biology 13: 1282-1292.

Meehl, G. A., J. M. Arblaster, and C. Tebaldi. 2005. Understanding future patterns of increased precipitation intensity in climate model simulations. Geophysical Research Letters Volume 32, L18719. 4 pages.

Moll, E. O., and J. M. Legler. 1971. The life history of a neotropical slider turtle, Pseudemys scripta (Scheopff) in Panama. Bulletin of the Los Angeles County Museum of Natural History and Science 11: 1-102.

Morris, W. F., C. A. Pfister, S. Tuljapurkar, C. V. Haridas, C. Boggs, M. S. Boyce, E. M. Bruna, D. R. Church, T. Coulson, D. F. Doak, S. Forsyth, J-M. Gaillard, C. C. Horvitz, S. Kalisz, B. E. Kendall, T. M. Knight, C. T. Lee, and E. S. Menges. 2008. Longevity can buffer plant and animal populations against changing climatic variability. Ecology 89: 19-25.

Nichols, J. T. 1939. Range and homing of individual box turtles. Copeia 1939: 125-127.
Pluto, T. G., and E. D. Bellis. 1988. Seasonal and annual movements of riverine Map Turtles, Graptemys geographica. Journal of Herpetology 22: 152-158.

Quinn, G. P., and M. J. Keough. 2002. Experimental Design and Data Analysis for Biologists. Cambridge University Press, Cambridge, UK.

Rathbun, G. B., N. J. Scott, and T. G. Murphey. 2002. Terrestrial habitat use by Pacific Pond Turtles in a Mediterranean climate. Southwestern Naturalist 47: 225-235.

Rivera, G. 2008. Ecomorphological variation in shell shape of the freshwater turtle Pseudemys concinna inhabiting different aquatic flow regimes. Integrative and Comparative Biology 48: 769-787.

Saumure, R. A. 2004. Spatial ecology and conservation of the North American Wood Turtle (Glyptemys insculpta) in a fragmented agri-forested landscape. Unpublished Ph.D. dissertation, McGill University; Montreal, Quebec.

Saumure, R. A., R. D. Titman, and T. B. Herman. 2007. Effects of haying and agricultural practices on a declining species: the North American Wood Turtle, Glyptemys insculpta. Biological Conservation 135: 581-591.

Selman, W., and C. Qualls. 2008. The impacts of Hurricane Katrina on a population of Yellow-blotched Sawbacks (Graptemys flavimaculata) in the lower Pascagoula River. Herpetological Conservation and Biology 3: 224-230.

Stickel, L. F. 1948. Observations of the effect of floods on animals. Ecology 29: 505-507.

Stickel, L. F. 1978. Changes in a box turtle population during three decades. Copeia 1978: 221-225.

Strange, E. M., P. B. Moyle, and T. C. Foin. 1992. Interactions between stochastic and deterministic processes in stream fish community assembly. Environmental Biology of Fishes 36: 1-15.

Sweeten, S. E. 2008. Home range, hibernacula fidelity, and best management practices for Wood Turtles (Glyptemys insculpta) in Virginia. Unpublished M.S. thesis, James Madison University, Harrisonburg, Virginia.

Walde, A. D., J. R. Bider, D. Masse, R. A. Saumure, and R. D. Titman. 2007. Nesting ecology and hatching success of the Wood Turtle, Glyptemys insculpta, in Québec. Herpetological Conservation and Biology 2: 49-60.

Watterson, I. G. 2005. Simulated changes due to global warming in the variability of precipitation, and their interpretation using a gamma-distributed stochastic model. Advances in Water Resources 28: 1368-1381.

Wong, S. T. 1963. A multivariate statistical model for predicting annual floods in New England. Annals of the Association of American Geographers 53: 298-311.

Received 21 February 2009

Accepted 18 July 2010 